Article

\title{
Antifungal Activity of Biocontrol Agents In Vitro and Potential Application to Reduce Mycotoxins (Aflatoxin B1 and Ochratoxin A)
}

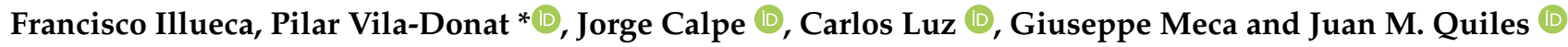 \\ Laboratory of Food Chemistry and Toxicology, Faculty of Pharmacy, University of Valencia, Av. Vicent Andrés \\ Estellés s/n, 46100 Burjassot, Spain; franima3@alumni.uv.es (F.I.); jorge.calpe@uv.es (J.C.); carlos.luz@uv.es (C.L.); \\ giuseppe.meca@uv.es (G.M.); Juan.Quiles@uv.es (J.M.Q.) \\ * Correspondence: pilar.vila@uv.es
}

check for updates

Citation: Illueca, F.; Vila-Donat, P.; Calpe, J.; Luz, C.; Meca, G.; Quiles, J.M. Antifungal Activity of Biocontrol Agents In Vitro and Potential Application to Reduce Mycotoxins (Aflatoxin B1 and Ochratoxin A). Toxins 2021, 13, 752. https://doi.org/ $10.3390 /$ toxins 13110752

Received: 12 August 2021

Accepted: 21 October 2021

Published: 23 October 2021

Publisher's Note: MDPI stays neutral with regard to jurisdictional claims in published maps and institutional affiliations.

Copyright: (C) 2021 by the authors Licensee MDPI, Basel, Switzerland. This article is an open access article distributed under the terms and conditions of the Creative Commons Attribution (CC BY) license (https:/ / creativecommons.org/licenses/by/ $4.0 /)$.

\begin{abstract}
Food bio-preservatives are requested as substituents of chemical pesticides in food. The aim of this study was to carry out a screening of twenty biocontrol agents (BCAs) for their potential fungicidal activity in vitro. Twenty BCAs were tested against ten pathogenic fungi. Some of the cell-free supernatants (CFS) tested showed in vitro antifungal activity versus pathogenic fungi. The highest fungicidal activity was observed in the fermented CFS of Paenibacillus chibensis CECT 375, Bacillus amyloliquefaciens CECT 493, and Pantoea agglomerans CECT 850, which showed a minimum inhibitory concentration (MIC) and minimum fungicidal concentration (MFC) values of 125 and $250 \mathrm{~g} / \mathrm{L}$, respectively. The compounds responsible for the antifungal activity, such as organic and phenolic acids, were determined. Lactic acid, acetic acid, benzoic acid, and phenyllactic acid among others can be related to antifungal activity. HPLC-MS/MS analysis showed a reduction of ochratoxin A (OTA) and aflatoxin $\mathrm{B}_{1}\left(\mathrm{AFB}_{1}\right)$ up to $26 \%$ (Paenibacillus alvei CECT 2 ) and $55 \%$ (Paenibacillus polymyxa CECT 155), respectively. The present study prompts that metabolism products of BCAs are propitious for the bioconservation of food, due to their ability to reduce the proliferation of mycotoxigenic fungi and mycotoxins production.
\end{abstract}

Keywords: biocontrol agents; antifungal; mycotoxins; reduction; in vitro; bio-preservation

Key Contribution: The findings of the present study confirms that some of the BCAs tested has antifungal and antimycotoxigenic activity probably due to the bioactive compounds produced during the fermentation process. Hence this study provide new knowledge for the biotechnological use of BCAs, since they could be promising for the bioconservation of food, contributing to natural al-ternatives.

\section{Introduction}

Fungi contamination remains a significant issue for the food industry due to their ability to degrade food and produce mycotoxins [1]. Fungal contamination of crops occurs at various stages during pre-harvest and postharvest, producing economic losses for farming and health problems in animals and humans [2-4]. It is estimated that about $10 \%$ of world basic staples are lost due to fungal contamination [5].

From the toxicological perspective, the most significant mycotoxins are aflatoxins. Aflatoxins are toxic metabolites mainly produced by Aspergillus flavus and Aspergillus parasiticus. Among them, aflatoxin $\mathrm{B}_{1}\left(\mathrm{AFB}_{1}\right)$ is the most worrisome. It has been classified as a group 1 compound, due to its carcinogenic effect, by the International Agency for Research on Cancer (IARC) [6]. In long-term exposure, this mycotoxin is associated to liver carcinoma in humans [7,8]. Another concerning mycotoxin is ochratoxin A (OTA), which is a nephrotoxic substance. It also possesses teratogenic, immunotoxic, and possibly neurotoxic properties. IARC classifies OTA as a possibly carcinogenic compound in humans 
(group 2B) [9]. These mycotoxins are still present in high and low levels in food and feed, causing a diversity of adverse effects, from acute to chronic, both in humans and animals $[4,10]$.

The use of synthetic fungicides has been the most common tool to fight this type of food deterioration, but its use has certain objections [11]. Pesticides have helped reduce crop loss caused by several infections and pests. However, constant usage of the same chemicals causes undesirable effects, such as pesticide resistance and environmental degradation, urging the need for alternative strategies that can protect crop health sustainably. In addition to the above mentioned, the consumer and public authorities demand the reduction in the use of chemical pesticides, encouraging us toward environmentally safe and sustainable substances for food preservation [12].

Scientific evidence related to the biological control indicates the ability of microorganisms such as yeast, bacteria, and fungi to mitigate mycotoxins by preventing their presence in animal feed and food of animal origin [10]. Microbial decontamination by BCAs is becoming a trust strategy contributing to food safety. Some bacteria genera such as Bacillus, Pseudomonas, Stenotrophomonas, and Streptomyces and fungi belonging to the genus Trichoderma act against a wide range of plant pathogens in an environmentally sustainable manner [13]. Several studies have screened the efficacy of potential microorganisms for mycotoxin control; however, the vast majority of investigated bacteria were mainly lactic acid bacteria (LABs) [1,14-19]. Non-lactic acid bacteria such as Bacillus spp. can also inhibit fungi growth and mycotoxin production [20]. Recently, Calvo et al. (2017) showed that Bacillus amyloliquefaciens BUZ-14 produce several bioactive compounds with high fungicidal activity such as lipopeptides and several polyketides, and their results indicated that B. amyloliquefaciens was promising BCA for postharvest fruit diseases [20]. BCAs act on competitive exclusion of mycotoxigenic pathogens, producing metabolites that may inhibit the colonization of crops and reduce the capability of mycotoxin production [13].

Given the rising interest in the use of natural microorganisms as an alternative to synthetic pesticides and the potential of BCAs, the aims of the present work were: (a) to evaluate the antifungal activity of twenty BCAs (bacteria, yeast, and fungi) against ten different fungal pathogenic species (b) to investigate the phenolic and organic acids produced by these bioactive strains and (c) to analyze the mycotoxin $\mathrm{AFB}_{1}$ and OTA reduction in vitro. The use of different $B C A s$ could represent an essential food preservation strategy as well as become the main alternative to chemical preservatives in food.

\section{Results and Discussion}

\subsection{In Vitro Antifungal Activity of Biocontrol Strains}

The overlay assay showed a high antifungal activity of twenty isolated BCAs versus Penicillium, Aspergillus, Fusarium, and Alternaria species (ten in total) expressed as percentage of inhibition after seven days with respect to the control. The strains Paenibacillus polymyxa CECT 155 and Metschnikowia pulcherrima CECT 10408 showed percentage of inhibition (up to $20 \%$ ) for all pathogens tested, even reaching $50 \%$ of inhibition in most cases with the exception of Aspergillus flavus (ITEM 8111) (Table 1). P. polymyxa CECT 155, Pantoea agglomerans CECT 850, M. pulcherrima CECT 1691, and CECT 10408 evidenced the highest antifungal activities against almost all Fusarium pathogenic fungi tested. $P$. polymyxa CECT 155 showed percentage inhibition of 50.5\%, $48.2 \%, 40.3 \%$, and $46 \%$ for Fusarium graminerarum, Fusarium poae, Fusarium verticilloides, and Fusarium langsethiae, respectively. P. agglomerans inhibited $47.4 \%$ of Fusarium sporotrichoides, whereas strains of M. pulcherrima (CECT 1691 and CECT 10408) showed inhibition of $50.4 \%$ and $50.1 \%$ for Fusarium proliferatum, respectively (Table 1). 


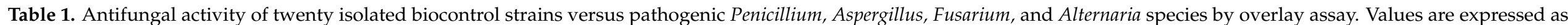
percentage of inhibition after 7 days \pm standard deviation. $\%$ Inhibition $=($ Diameter of control - Diameter of agent $) /$ Diameter of control.

\begin{tabular}{|c|c|c|c|c|c|c|c|c|c|c|}
\hline \multirow[b]{2}{*}{ Pathogen } & \multicolumn{10}{|c|}{ \% Inhibition } \\
\hline & $\begin{array}{l}\text { F. sporotri- } \\
\text { chioides } \\
\text { ITEM } \\
12168\end{array}$ & $\begin{array}{l}\text { F. gramin- } \\
\text { earum } \\
\text { ITEM } \\
126\end{array}$ & $\begin{array}{c}F . \\
\text { proliferatum } \\
\text { ITEM } \\
12072\end{array}$ & $\begin{array}{c}\text { F. poae } \\
\text { ITEM } \\
9151\end{array}$ & $\begin{array}{l}\text { F. verticil- } \\
\text { lioides } \\
\text { ITEM } \\
12043\end{array}$ & $\begin{array}{c}F . \\
\text { langsethiae } \\
\text { ITEM } \\
11031\end{array}$ & $\begin{array}{c}P . \\
\text { verrucosum } \\
\text { CECT } \\
2913\end{array}$ & $\begin{array}{l}\text { B. cinerea } \\
\text { CECT } \\
20973\end{array}$ & $\begin{array}{l}\text { A. flavus } \\
\text { ITEM } \\
8111\end{array}$ & $\begin{array}{l}\text { A. alternato } \\
\text { ITEM } \\
8121\end{array}$ \\
\hline Diameter control (cm) & 8.5 & 6.5 & 7.4 & 6.6 & 5 & 5.3 & 1.6 & 7.7 & $\mathrm{Nd}$ & 5.5 \\
\hline \multicolumn{11}{|l|}{ Biocontrol agents } \\
\hline P. polymixa CECT 153 & $\mathrm{Nd}$ & $\mathrm{Nd}$ & $\mathrm{Nd}$ & $8.3 \pm 0.2$ & $\mathrm{Nd}$ & 8.1 & $\mathrm{Nd}$ & $10.2 \pm 0.1$ & $\mathrm{Nd}$ & $\mathrm{Nd}$ \\
\hline B. thuringiensis CECT 197 & $40.1 \pm 0.1$ & $20.3 \pm 0.2$ & $20.2 \pm 0.2$ & $18.5 \pm 0.2$ & $18.2 \pm 0.2$ & $25.2 \pm 0.3$ & $\mathrm{Nd}$ & $18.2 \pm 0.2$ & $\mathrm{Nd}$ & $15.4 \pm 0.2$ \\
\hline P. chibensis CECT 375 & $18.2 \pm 0.2$ & $17.4 \pm 0.2$ & $19.2 \pm 0.2$ & $16.2 \pm 0.1$ & $16.3 \pm 0.1$ & $25.1 \pm 0.2$ & $\mathrm{Nd}$ & $20.2 \pm 0.1$ & $\mathrm{Nd}$ & $19.3 \pm 0.3$ \\
\hline P. alvei CECT 2 & $16.5 \pm 0.1$ & $15.4 \pm 0.1$ & $16.6 \pm 0.1$ & $16.7 \pm 0.2$ & $16.2 \pm 0.2$ & $19.4 \pm 0.2$ & $\mathrm{Nd}$ & $16.5 \pm 0.4$ & $\mathrm{Nd}$ & $13.8 \pm 0.2$ \\
\hline B. licheniformis CECT 20 & $16.3 \pm 0.2$ & $17.5 \pm 0.2$ & $18.7 \pm 0.2$ & $16.9 \pm 0.1$ & $\mathrm{Nd}$ & $16.4 \pm 0.1$ & $\mathrm{Nd}$ & $16.2 \pm 0.1$ & $\mathrm{Nd}$ & $14.7 \pm 0.1$ \\
\hline B. megaterium CECT 44 & $16.2 \pm 0.1$ & $19.2 \pm 0.1$ & $18.5 \pm 0.1$ & $11.4 \pm 0.3$ & $\mathrm{Nd}$ & $18.3 \pm 0.2$ & $\mathrm{Nd}$ & $20.2 \pm 0.3$ & $\mathrm{Nd}$ & $16.3 \pm 0.3$ \\
\hline B. subtilis CECT 499 & $25.8 \pm 0.3$ & $20.2 \pm 0.3$ & $21.2 \pm 0.3$ & $25.2 \pm 0.2$ & $\mathrm{Nd}$ & $18.3 \pm 0.1$ & $\mathrm{Nd}$ & $21.5 \pm 0.2$ & $\mathrm{Nd}$ & $13.9 \pm 0.2$ \\
\hline B. amyloliquefaciens CECT 493 & $25.3 \pm 0.2$ & $19.2 \pm 0.2$ & $22.8 \pm 0.2$ & $22.2 \pm 0.2$ & $20.2 \pm 0.1$ & $16.2 \pm 0.2$ & $\mathrm{Nd}$ & $33.2 \pm 0.1$ & $\mathrm{Nd}$ & $20.3 \pm 0.2$ \\
\hline P. agglomerans CECT 850 & $47.4 \pm 0.1$ & $40.3 \pm 0.1$ & $37.6 \pm 0.3$ & $20.3 \pm 0.1$ & $21.2 \pm 0.1$ & $16.6 \pm 0.1$ & $\mathrm{Nd}$ & $25.3 \pm 0.3$ & $\mathrm{Nd}$ & $22.2 \pm 0.1$ \\
\hline S. griseus CECT 3276 & $25.9 \pm 0.3$ & $19.4 \pm 0.2$ & $20.5 \pm 0.2$ & $22.2 \pm 0.2$ & $\mathrm{Nd}$ & $\mathrm{Nd}$ & $\mathrm{Nd}$ & $18.5 \pm 0.2$ & $\mathrm{Nd}$ & $14.2 \pm 0.1$ \\
\hline P. syringae CECT 312 & $22.5 \pm 0.2$ & $35.3 \pm 0.2$ & $25.3 \pm 0.1$ & $21.3 \pm 0.1$ & $19.4 \pm 0.2$ & $\mathrm{Nd}$ & $\mathrm{Nd}$ & $16.2 \pm 0.2$ & $\mathrm{Nd}$ & $16.6 \pm 0.3$ \\
\hline P. syringae CECT 4390 & $22.1 \pm 0.2$ & $21.2 \pm 0.2$ & $\mathrm{Nd}$ & $\mathrm{Nd}$ & $18.6 \pm 0.1$ & $\mathrm{Nd}$ & $\mathrm{Nd}$ & $16.3 \pm 0.1$ & $\mathrm{Nd}$ & $35.4 \pm 0.1$ \\
\hline P. syringae CECT 4393 & $20.2 \pm 0.2$ & $20.1 \pm 0.2$ & $\mathrm{Nd}$ & $\mathrm{Nd}$ & $17.8 \pm 0.1$ & $\mathrm{Nd}$ & $\mathrm{Nd}$ & $16.1 \pm 0.1$ & $\mathrm{Nd}$ & $16.0 \pm 0.2$ \\
\hline C. sake CECT 1044 & $31.2 \pm 0.1$ & $40.3 \pm 0.1$ & $48.2 \pm 0.1$ & $40.3 \pm 0.2$ & $20.3 \pm 0.2$ & $30.2 \pm 0.1$ & $\mathrm{Nd}$ & $19.2 \pm 0.1$ & $\mathrm{Nd}$ & $20.1 \pm 0.2$ \\
\hline C. sake CECT 10034 & $45.2 \pm 0.2$ & $39.3 \pm 0.1$ & $45.2 \pm 0.2$ & $40.2 \pm 0.1$ & $39.2 \pm 0.1$ & $30.3 \pm 0.1$ & $\mathrm{Nd}$ & $33.3 \pm 0.1$ & $\mathrm{Nd}$ & $33.5 \pm 0.1$ \\
\hline C. oleophila CECT 11891 & $45.1 \pm 0.2$ & $35.2 \pm 0.2$ & $45.4 \pm 0.1$ & $40.2 \pm 0.2$ & $39.2 \pm 0.1$ & $35.3 \pm 0.2$ & $\mathrm{Nd}$ & $20.4 \pm 0.3$ & $\mathrm{Nd}$ & $21.4 \pm 0.2$ \\
\hline M. pulcherrima CECT 1691 & $45.2 \pm 0.2$ & $40.2 \pm 0.1$ & $50.4 \pm 0.2$ & $41.3 \pm 0.2$ & $40.3 \pm 0.1$ & $40.5 \pm 0.1$ & $\mathrm{Nd}$ & $19.2 \pm 0.2$ & $\mathrm{Nd}$ & $30.5 \pm 0.1$ \\
\hline M. pulcherrima CECT 10408 & $45.0 \pm 0.2$ & $40.3 \pm 0.2$ & $50.1 \pm 0.3$ & $40.2 \pm 0.1$ & $39.2 \pm 0.1$ & $40.2 \pm 0.2$ & $20 \pm 0.2$ & $40.6 \pm 0.4$ & $\mathrm{Nd}$ & $20.3 \pm 0.3$ \\
\hline
\end{tabular}

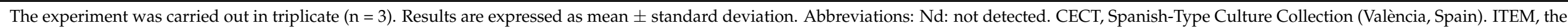

Agro-Food Microbial Culture Collection of the Institute of Sciences and Food Production (Bari, Italy). 
On the other hand, some of the CFS (cell-free supernatants) of biocontrol microorganisms tested proved antifungal activity against pathogenic fungi in the solid medium diffusion agar test (Table 2). The highest antifungal activity was detected in the CFS of Paenibacillius chibensis and P. agglomerans, which inhibited the growth of almost all the pathogens tested, and Bacillus amyloliquefaciens, which inhibited the growth of $F$. Poae and F. graminearum by the diffusion agar method (Table 2). The antifungal capacity of P. chibensis against Fusarium verticilloides, F. graminearum, and F. langsethiae was proved, as can be clearly seen in Figure 1. In accordance with these results, other authors evidenced the antifungal activity of bacteria against different fungi species by using the diffusion agar method [1,16,19] and overlay method [17]. However, none of these studies used such selection of BCAs including non-lactic acid bacteria, yeast, and fungi. With the aim to quantify the potential antifungal activity of the three bioactive CFS (P. chibensis, P. agglomerans, and B. amyloliquefaciens), the minimum inhibitory concentration (MIC) and minimum fungicidal concentration (MFC) values were determined. The results of MIC-MFC tests are described in Table 3. In line with qualitative results, the three CFS tested showed inhibitory activity reaching MIC-MFC values from 125 to $250 \mathrm{~g} / \mathrm{L}$ against almost all the fungi tested (Penicillium spp., Aspergillus spp., Fusarium spp., and Alternaria spp.). The three biocontrol strains tested (P. chibensis, B. amyloliquefaciens, and P. agglomerans) showed MIC and CFS values of 125 and $250 \mathrm{~g} / \mathrm{L}$, respectively, against $F$. langsethiae. Meanwhile, the CFS of strain PA850 showed MIC and CFS values (125 and $250 \mathrm{~g} / \mathrm{L}$, respectively) against Penicillium and Alternaria strains. P. chibensis showed such values against $F$. graminearum and A. flavus. These results were in accordance with Luz et al. (2020) [16], who evidenced that the Fusarium genus was the most sensitive specie to the bioactive compounds present in the fermented CFS of Lactobacillus plantarum. In the same work, the authors showed MFC values of $250 \mathrm{~g} / \mathrm{L}$ from LABs against Aspergillus [16]. In the same line, Izzo et al. (2020) investigated the inhibitory effect of sweet whey fermented by Lactobacillus plantarum strains against fungal growth (Fusarium and Aspergillus), and the results of the MIC-MFC varied between 1.95 and $250 \mathrm{~g} / \mathrm{L}$, whereas the value of MFC was in the range of 4 to $250 \mathrm{~g} / \mathrm{L}$ [12] Hence, MIC and MFC values obtained in this work are similar comparing with values previously reported in which LABs were tested to increase the shelf life of food $[12,16,19]$. These results suggest the possible use of BCAs as a source of new preservatives of natural origin to incorporate in food matrices for the purpose of improving the shelf life. However, due to the Good Hygienic and Manufacturing Practices required for food production and their low microbial load, the use of concentrations significantly below the MIC and MFC values could also result in a significant increase in shelf life.

a)

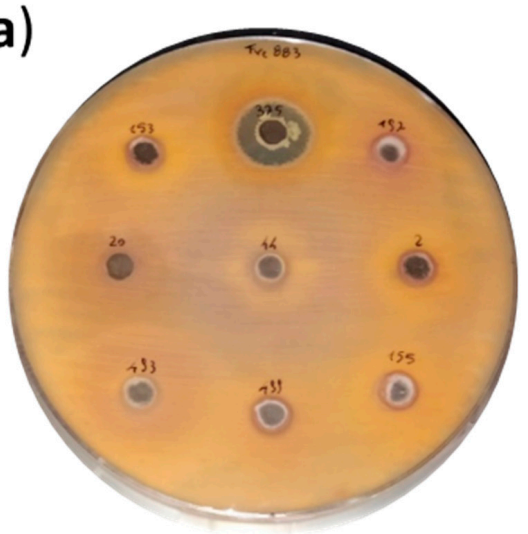

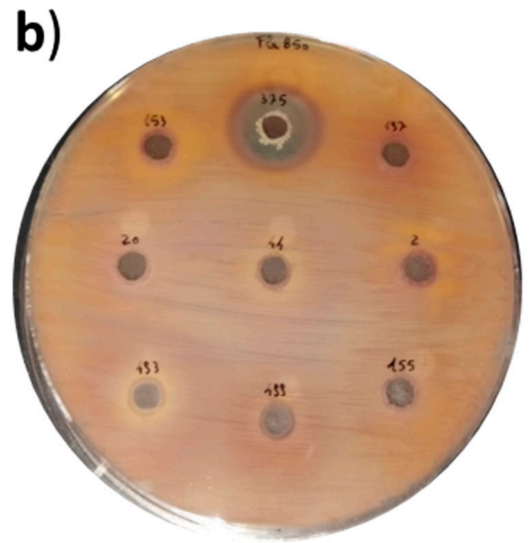

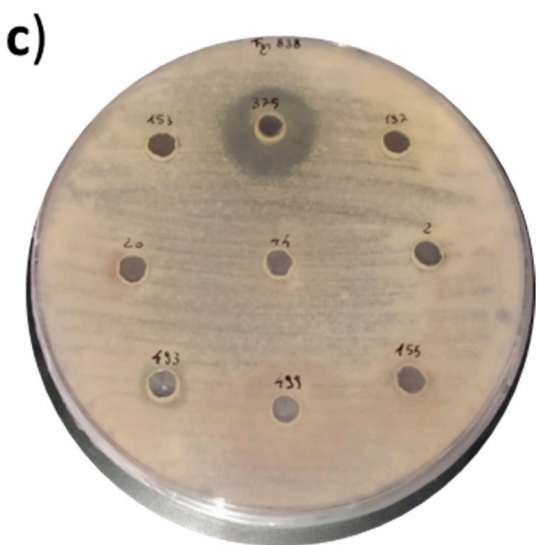

Figure 1. Example of antifungal activity of Paenibacillus chibensis CECT 375 against: (a) Fusarium verticilloides ITEM 12044, (b) Fusarium graminearum ITEM 126, and (c) Fusarium langsethiae ITEM 11031 determined by the diffusion agar method. 


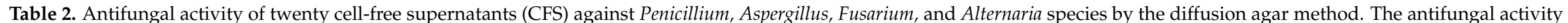

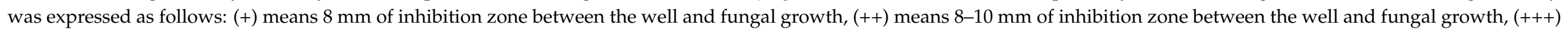
means $>10 \mathrm{~mm}$ of inhibition zone between the well and fungal growth. The well radius was $5 \mathrm{~mm}$.

\begin{tabular}{|c|c|c|c|c|c|c|c|c|c|c|}
\hline Pathogen & $\begin{array}{l}\text { F. sporotri- } \\
\text { chioides } \\
\text { ITEM } \\
12168\end{array}$ & $\begin{array}{l}\text { F. gramin- } \\
\text { earum } \\
\text { ITEM } \\
126\end{array}$ & $\begin{array}{c}F . \\
\text { proliferatum } \\
\text { ITEM } \\
12072\end{array}$ & $\begin{array}{c}\text { F. poae } \\
\text { ITEM } 9151\end{array}$ & $\begin{array}{l}\text { F. verticil- } \\
\text { lioides } \\
\text { ITEM } \\
12043\end{array}$ & $\begin{array}{c}F . \\
\text { langsethiae } \\
\text { ITEM } \\
11031\end{array}$ & $\begin{array}{c}P . \\
\text { verrucosum } \\
\text { CECT } \\
2913\end{array}$ & $\begin{array}{l}\text { B. cinerea } \\
\text { CECT } 20973\end{array}$ & $\begin{array}{l}\text { A. flavus } \\
\text { ITEM } 8111\end{array}$ & $\begin{array}{l}\text { A. alternata } \\
\text { ITEM } 8121\end{array}$ \\
\hline P. polymixa CECT 153 & - & - & - & - & - & - & - & - & - & - \\
\hline P. polymixa CECT 155 & - & - & - & - & - & - & - & - & - & - \\
\hline B. thuringiensis CECT 197 & - & - & - & - & - & - & - & - & - & - \\
\hline P. chibensis CECT 375 & - & +++ & - & +++ & +++ & +++ & +++ & - & +++ & ++ \\
\hline P. alvei CECT 2 & - & - & - & - & - & - & - & - & - & - \\
\hline B. licheniformis CECT 20 & - & - & - & - & + & - & - & - & - & - \\
\hline B. megaterium CECT 44 & - & - & - & - & - & - & - & - & - & - \\
\hline B. subtilis CECT 499 & - & - & - & - & - & - & - & - & - & - \\
\hline B. amyloliquefaciens CECT 493 & - & +++ & - & +++ & - & - & - & - & - & + \\
\hline P. agglomerans CECT 850 & ++ & + & ++ & + & + & ++ & +++ & +++ & - & +++ \\
\hline S. griseus CECT 3276 & - & - & - & - & - & - & - & - & - & - \\
\hline S. calvus CECT 3271 & - & - & - & - & - & - & - & - & - & - \\
\hline P. syringae CECT 312 & - & - & - & - & - & - & - & - & - & - \\
\hline C. sake CECT 1044 & - & - & - & - & - & - & - & - & - & - \\
\hline C. sake CECT 10034 & - & - & - & - & - & - & - & - & - & - \\
\hline C. oleophila CECT 11891 & - & - & - & - & - & - & - & - & - & - \\
\hline M. pulcherrima CECT 1691 & - & - & - & - & - & - & - & - & - & - \\
\hline M. pulcherrima CECT 10408 & - & - & - & - & - & - & - & - & - & - \\
\hline
\end{tabular}

Abbreviations: CECT, Spanish Type Culture Collection (València, Spain). ITEM, the Agro-Food Microbial Culture Collection of the Institute of Sciences and Food Production (Bari, Italy). 
Table 3. Minimum Inhibitory Concentration (MIC) and Minimum Fungicidal Concentration (MFC) for three lyophilized CFS fermented by biocontrol strains (PCH375, BA493, and PA850) versus Penicillium, Aspergillus, Fusarium, and Alternaria species. The results are expressed as (g/L).

\begin{tabular}{ccccccc}
\hline \multirow{2}{*}{ Fungi } & \multicolumn{7}{c}{ Biocontrol Agents } \\
\cline { 2 - 7 } & \multicolumn{2}{c}{$\begin{array}{c}\text { P. chibensis } \\
\text { CECT 375 }\end{array}$} & \multicolumn{2}{c}{ B. amyloliquefaciens } & \multicolumn{2}{c}{ P. agglomerans } \\
CECT 493 & \multicolumn{2}{c}{ CECT 850 } \\
\cline { 2 - 7 } & MIC & MFC & MIC & MFC & MIC & MFC \\
\hline F. graminearum ITEM 126 & 125 & 250 & $\mathrm{Nd}$ & $\mathrm{Nd}$ & $\mathrm{Nd}$ & $\mathrm{Nd}$ \\
F. sporotrichioides ITEM 12168 & $\mathrm{Nd}$ & $\mathrm{Nd}$ & $\mathrm{Nd}$ & $\mathrm{Nd}$ & $\mathrm{Nd}$ & $\mathrm{Nd}$ \\
F. langsethiae ITEM 11031 & 125 & 250 & 125 & 250 & 125 & 250 \\
F. poae ITEM 9151 & 125 & 250 & $\mathrm{Nd}$ & $\mathrm{Nd}$ & 125 & 250 \\
F. verticillioides ITEM 12043 & 125 & 250 & $\mathrm{Nd}$ & $\mathrm{Nd}$ & 125 & $\mathrm{Nd}$ \\
P. verrucosum CECT 2913 & $\mathrm{Nd}$ & $\mathrm{Nd}$ & $\mathrm{Nd}$ & $\mathrm{Nd}$ & 125 & 250 \\
A. alternata ITEM 8121 & $\mathrm{Nd}$ & $\mathrm{Nd}$ & $\mathrm{Nd}$ & $\mathrm{Nd}$ & 125 & 250 \\
A. flavus ITEM 8111 & 125 & 250 & $\mathrm{Nd}$ & $\mathrm{Nd}$ & $\mathrm{Nd}$ & $\mathrm{Nd}$ \\
\hline
\end{tabular}

Abbreviations: Nd: not detected. CECT, Spanish Type Culture Collection (València, Spain). ITEM, the Agro-Food Microbial Culture Collection of the Institute of Sciences and Food Production (Bari, Italy).

In contrast, other studies, such as Rizzello, et al. (2011) [21], evidenced lower MIC values $(2.5-15.2 \mathrm{~g} / \mathrm{L})$ for the water-soluble extract from sourdough fermented by LABs when proved against Penicillium spp.

\subsection{Identification of Antifungal Compounds in CFS}

In this study, two organic acids and seven phenolic acids were identified in CFS fermented by twenty and nine biocontrol strains, respectively (Tables 4 and 5). These compounds were determined by HPLC-qTOF-MS. The organic acids in lyophilized CFS fermented by BCAs are indicated in Table 4 . Two organic acids were determined: lactic acid and acetic acid. All isolated BCAs produced lactic acid, reaching concentrations from 129 to $3491 \mathrm{mg} / \mathrm{L}$. The BCAs with the highest lactic acid production were Bacillus thuringiensis (3491 mg/L), P. polymyxa CECT 155 (3372 mg/L), P. polymyxa CECT 153 (2622 mg/L), Bacillus subtilis (2553 mg/L), and Bacillus megaterium (2350 mg/L). The production of acetic acid (203-1873 mg/L) was determined only in five CFS, the highest concentration produced being P. polymyxa CECT 153 and P. polymyxa CECT 155 (1873 mg/L and $1271 \mathrm{mg} / \mathrm{L}$, respectively). Table 5 lists the nine fermented CFS in which phenolic acids were detected. These phenolic acids detected and quantified in the CFS were DL-3-phenyl lactic acid (PLA), benzoic acid, 1-2-dydroxybenzene, hydroxycinnamic acid, p-coumaric acid, 3-4-dihydroxycinnamic acid, and protocatechuic acid. Some of these compounds have been previously reported as antifungal agents produced by LABs [18]. Benzoic acid was quantified in each CFS tested, and its concentration range was $0.004-0.067 \mathrm{~g} / \mathrm{L}$. The highest concentrations of benzoic acid were detected in P. alvei and P. polymyxa CECT 153 (0.067 and $0.060 \mathrm{~g} / \mathrm{L}$, respectively).

PLA was detected only in five CFS, and concentrations ranged from 0.058 to $0.844 \mathrm{~g} / \mathrm{L}$, among which the $B$. thuringiensis strain was the highest producer of PLA. In addition, 1-2-dyhdroxybenzene was quantified only in two CFS (B. amyloliquefaciens and P. chibensis), with values of $0.03-0.04 \mathrm{~g} / \mathrm{L}$, respectively. These results are in line with Rodriguez et al. (2008), who noticed the presence of 1-2-dyhdroxybenzene generated by enzymes of Lactobacillus plantarum [22]. The fact that P. polymyxa CECT 155 and P. chibensis were the only CFS that produced dydroxyhydrocinnamic $(0.022 \pm 0.06 \mathrm{~g} / \mathrm{L})$ and protocatechuic acid $(0.008 \pm 0.01 \mathrm{~g} / \mathrm{L})$ respectively, should be highlighted. 
Table 4. Identification and quantification of organic acids $(\mathrm{mg} / \mathrm{L})$ produced by the twenty bacteria in CFS. The results are expressed as mean \pm standard deviation.

\begin{tabular}{ccc}
\hline Biocontrol & \multicolumn{2}{c}{ Organic Acids (mg/L) } \\
\cline { 2 - 3 } Agents & Lactic Acid & Acetic Acid \\
\hline P. polymixa CECT 153 & $2622 \pm 0.12$ & $1873 \pm 0.15$ \\
P. polymixa CECT 155 & $3372 \pm 0.30$ & $1271 \pm 0.12$ \\
B. thuringiensis CECT 197 & $3491 \pm 0.05$ & $\mathrm{Nd}$ \\
P. chibensis CECT 375 & $1676 \pm 0.01$ & $\mathrm{Nd}$ \\
P. alvei CECT 2 & $384 \pm 0.07$ & $\mathrm{Nd}$ \\
B. licheniformis CECT 20 & $288 \pm 0.04$ & $\mathrm{Nd}$ \\
B. megaterium CECT 44 & $2350 \pm 0.04$ & $\mathrm{Nd}$ \\
B. subtilis CECT 499 & $2553 \pm 0.02$ & $\mathrm{Nd}$ \\
B. amyloliquefaciens CECT 493 & $1251 \pm 0.1$ & $\mathrm{Nd}$ \\
P. agglomerans CECT 850 & $844 \pm 0.1$ & $\mathrm{Nd}$ \\
S. griseus CECT 3276 & $1327 \pm 0.06$ & $\mathrm{Nd}$ \\
S. calvus CECT 3271 & $1411 \pm 0.08$ & $\mathrm{Nd}$ \\
P. syringae CECT 312 & $788 \pm 0.11$ & $415 \pm 0.02$ \\
P. syringae CECT 4390 & $670 \pm 0.06$ & $203 \pm 0.01$ \\
P. syringae CECT 4393 & $913 \pm 0.20$ & $208 \pm 0.11$ \\
C. sake CECT 1044 & $469 \pm 0.06$ & $\mathrm{Nd}$ \\
C. sake CECT 10034 & $416 \pm 0.06$ & $\mathrm{Nd}$ \\
C. oleophila CECT 11891 & $129 \pm 0.01$ & $\mathrm{Nd}$ \\
M. pulcherrima CECT 1691 & $230 \pm 0.01$ & $\mathrm{Nd}$ \\
M. pulcherrima CECT 10408 & $1675 \pm 0.03$ & $\mathrm{Nd}$ \\
\hline
\end{tabular}

The experiment was carried out in triplicate $(n=3)$. Results are expressed as mean \pm standard deviation. Abbreviations: Nd: not detected. CECT, Spanish Type Culture Collection (València, Spain).

Table 5. Identification and quantification of phenolic acids $(\mathrm{g} / \mathrm{L})$ produced by bacteria in CFS. The results are expressed as mean \pm standard deviation.

\begin{tabular}{|c|c|c|c|c|c|c|c|c|c|}
\hline \multirow[b]{2}{*}{ Phenolic Acids } & \multicolumn{9}{|c|}{ Biocontrol Agents } \\
\hline & $\begin{array}{l}\text { B. thuringensis } \\
\text { CECT } 197\end{array}$ & $\begin{array}{l}\text { P. polymyxa } \\
\text { CECT } 153\end{array}$ & $\begin{array}{l}\text { P. chibensis } \\
\text { CECT } 375\end{array}$ & $\begin{array}{c}B . \\
\text { amyloquefaciens } \\
\text { CECT } 493\end{array}$ & $\begin{array}{l}\text { B. subtilis } \\
\text { CECT } 499\end{array}$ & $\begin{array}{l}\text { P. alvei } \\
\text { CECT } 2\end{array}$ & $\begin{array}{l}\text { B. licheniformis } \\
\text { CECT } 20\end{array}$ & $\begin{array}{l}\text { B. megaterium } \\
\text { CECT } 44\end{array}$ & $\begin{array}{l}\text { P. polymyxa } \\
\text { CECT } 155\end{array}$ \\
\hline Benzoic acid & $0.005 \pm 0.03$ & $0.060 \pm 0.06$ & $0.023 \pm 0.01$ & $0.004 \pm 0.02$ & $0.044 \pm 0.01$ & $0.067 \pm 0.02$ & $0.012 \pm 0.02$ & $0.047 \pm 0.01$ & $0.062 \pm 0.01$ \\
\hline $\begin{array}{l}\text { DL-3-Phenyllactic } \\
\text { acid }\end{array}$ & $0.844 \pm 0.06$ & $0.184 \pm 0.03$ & $\mathrm{Nd}$ & $\mathrm{Nd}$ & $\mathrm{Nd}$ & $0.195 \pm 0.01$ & $\mathrm{Nd}$ & $0.058 \pm 0.02$ & $0.297 \pm 0.02$ \\
\hline $\begin{array}{l}\text { 1-2-Dihydroxy } \\
\text { benzene }\end{array}$ & $\mathrm{Nd}$ & $\mathrm{Nd}$ & $0.040 \pm 0.01$ & $0.03 \pm 0.02$ & $\mathrm{Nd}$ & $\mathrm{Nd}$ & $\mathrm{Nd}$ & $\mathrm{Nd}$ & $\mathrm{Nd}$ \\
\hline $\begin{array}{l}\text { Hydroxi cinnamic } \\
\text { acid }\end{array}$ & $\mathrm{Nd}$ & $\mathrm{Nd}$ & $\mathrm{Nd}$ & $\mathrm{Nd}$ & $\mathrm{Nd}$ & $\mathrm{Nd}$ & $\mathrm{Nd}$ & $\mathrm{Nd}$ & $\mathrm{Nd}$ \\
\hline P-Coumaric acid & $0.002 \pm 0.01$ & $\mathrm{Nd}$ & $\mathrm{Nd}$ & $\mathrm{Nd}$ & $\mathrm{Nd}$ & $\mathrm{Nd}$ & $\mathrm{Nd}$ & $0.030 \pm 0.07$ & $\mathrm{Nd}$ \\
\hline $\begin{array}{l}\text { 3-4-Dihydroxyhy } \\
\text { drocinnamic }\end{array}$ & $\mathrm{Nd}$ & $\mathrm{Nd}$ & $\mathrm{Nd}$ & $\mathrm{Nd}$ & $\mathrm{Nd}$ & $\mathrm{Nd}$ & $\mathrm{Nd}$ & $\mathrm{Nd}$ & $0.022 \pm 0.06$ \\
\hline $\begin{array}{l}\text { Protocatechuic } \\
\text { acid }\end{array}$ & $\mathrm{Nd}$ & $\mathrm{Nd}$ & $0.008 \pm 0.01$ & $\mathrm{Nd}$ & $\mathrm{Nd}$ & $\mathrm{Nd}$ & $\mathrm{Nd}$ & $\mathrm{Nd}$ & $\mathrm{Nd}$ \\
\hline
\end{tabular}

The experiment was carried out in triplicate $(\mathrm{n}=3)$. Results are expressed as mean \pm standard deviation; Abbreviations: Nd: not detected. CECT, Spanish Type Culture Collection (València, Spain).

Our results pointed out that strains of P. polymyxa CECT 153, P. polymyxa CECT 155, P. chibensis, B. amyloliquefaciens, and P. alvei showed the highest capacity to produce organic and phenolic compounds. Like organic acid production, the phenolic acids data were associated with the observed antifungal activity of CFS. In fact, previous authors evidenced synergism between lactic acid and acetic acid [23], and between these and PLA regarding the potential antifungal activity [24].

Moreover, some of these phenolic compounds with antifungal activity, above described, have been linked to the ability to prevent mycotoxin production $[1,19,25,26]$.

\subsection{Antimycotoxigenic Activity of CFS}

Along with evaluating the qualitative and quantitative antifungal activity of CFS, the ability to reduce mycotoxins was investigated. The antimycotoxigenic activity was evaluated by using 20 biocontrol strains against $\mathrm{AFB}_{1}(1 \mathrm{mg} / \mathrm{L})$ and OTA $(1 \mathrm{mg} / \mathrm{L})$ after $48 \mathrm{~h}$ of exposure (Table 6). To our knowledge, this is the first work in which the antimycotoxigenic activity of 20 different BCAs against ten pathogens has been investigated. 
Table 6. Antimycotoxigenic activity of twenty biocontrol strains versus aflatoxin $\mathrm{B}_{1}\left(\mathrm{AFB}_{1}\right)$ and ochratoxin A (OTA) $(1 \mathrm{mg} / \mathrm{L})$ after $48 \mathrm{~h}$ of exposure.

\begin{tabular}{ccc}
\hline Biocontrol Agents & \% Reduction AFB $_{\mathbf{1}}$ & \% Reduction OTA \\
\hline P. polymixa CECT 153 & $11.19 \pm 0.9$ & $11.85 \pm 4.0$ \\
P. polymixa CECT 155 & $55.00 \pm 3.1$ & $18.78 \pm 11.6$ \\
B. thuringiensis CECT 197 & $12.71 \pm 0.2$ & $22.06 \pm 3.7$ \\
P. chibensis CECT 375 & $9.81 \pm 4.0$ & $7.33 \pm 6.2$ \\
P. alvei CECT 2 & $19.19 \pm 0.9$ & $22.80 \pm 2.4$ \\
B. licheniformis CECT 20 & $11.81 \pm 7.9$ & $26.50 \pm 4.4$ \\
B. megaterium CECT 44 & $28.87 \pm 24.0$ & $13.10 \pm 3.5$ \\
B. subtilis CECT 499 & $13.41 \pm 6.7$ & $13.67 \pm 7.0$ \\
B. amyloliquefaciens CECT 493 & $0.00 \pm 0.0$ & $10.30 \pm 7.7$ \\
P. agglomerans CECT 850 & $5.00 \pm 5.0$ & $7.26 \pm 3.2$ \\
S. griseus CECT 3276 & $3.51 \pm 2.3$ & $21.38 \pm 2.2$ \\
S. calvus CECT 3271 & $0.00 \pm 0.0$ & $10.96 \pm 0.8$ \\
P. syringae CECT 312 & $6.15 \pm 0.13$ & $16.06 \pm 7.5$ \\
P. syringae CECT 4390 & $28.09 \pm 1.6$ & $13.09 \pm 3.8$ \\
P. syringae CECT 4393 & $26.33 \pm 0.7$ & $4.73 \pm 9.2$ \\
C. sake CECT 1044 & $1.18 \pm 2.2$ & $7.33 \pm 3.3$ \\
C. sake CECT 10034 & $24.86 \pm 5.9$ & $10.07 \pm 6.6$ \\
C. oleophila CECT 11891 & $0.00 \pm 0.0$ & $18.69 \pm 3.5$ \\
M. pulcherrima CECT 1691 & $0.00 \pm 0.0$ & $7.19 \pm 3.5$ \\
M. pulcherrima CECT 10408 & $0.00 \pm 0.0$ & $8.41 \pm 4.7$ \\
\hline
\end{tabular}

As evidenced in Table 6, 11 out of 20 and 14 out of 20 BCAs tested showed $\mathrm{AFB}_{1}$ and OTA reduction above $10 \%$. The reduction of $\mathrm{AFB}_{1}$ was in the range of 1.2 to $55 \%$, and the reduction percentage of OTA ranging from 4.7 to $26.5 \%$. P. polymyxa CECT 155 showed the highest reduction (55\%) of $\mathrm{AFB}_{1}$ after $48 \mathrm{~h}$ of exposure. These values are slightly higher than those found in other studies testing biocontrol strains. Topcu et al. (2010) tested some non-lactic acid bacteria, specifically probiotic Enterococcus faecium M74 and EF031 strains, and observed a reduction of the $\mathrm{AFB}_{1}$ content of aqueous solution by $19-38 \%$ [27]. However, other authors noticed that a Bacillus subtilis strain decreased the $\mathrm{AFB}_{1}$ level of contaminated feed and food by $60-95 \%[28,29]$. These differences may be related to the type of biocontrol strain, days of exposure, and the presence or absence of a food matrix.

Moreover, in our study, P. alvei showed the highest reduction of OTA (26.5\%) after $48 \mathrm{~h}$ of exposure. Similar results were obtained by Shukla et al. (2018) who isolated Bacillus subtilis KU-153 from Kimchi (a traditional Korean fermented food) and investigated its ability to lessen OTA content in culture medium. They observed a reduction of OTA content in viable cells by $22 \%$. However, B. subtilis heat-treated cells proved a higher OTA reduction $(45 \%)$ [30].

As previously mentioned, these biocontrol strains were among the great producers of phenolic compounds; hence, the production of metabolites with antifungal activity may explain their anti-mycotoxigenic activity.

The present results suggested that metabolism products of BCAs, due to their potential to minimize the growth of mycotoxigenic fungi and the production of the mycotoxins, could be promising for the bioconservation of food.

\section{Conclusions}

In this study, twenty different BCAs were tested against ten mycotoxigenic fungi. In vitro experiments proved that $C F S$ fermented by isolated $B C A s$ has significant antifungal activity versus $P$. chibensis, B. amyloliquefaciens, and P. agglomerans. The organic (lactic and acetic acid) and phenolic acids (benzoic acid and PLA, among others) produced by BCAs showed antifungal activity against Fusarium spp., A. flavus, Penicillium verrucosum, and Alternaria alternata.

Furthermore, the use of $\mathrm{BCAs}$ partially reduced the presence of $\mathrm{AFB}_{1}$ and OTA, two mycotoxins of great concern to animal and human health that have been declared carcino- 
genic to humans. Specifically, the biocontrol strain of P. polymyxa CECT 155 decreased the in vitro incidence of $\mathrm{AFB}_{1}$ and OTA up to $55 \%$ and $20 \%$, respectively. The reduction of mycotoxins production is mainly due to the inhibition of fungal proliferation by the bioactive compounds produced during the fermentation process by BCAs. The present work suggests that both the studied BCA strains and their metabolism products, due to their potential to bring down the growth of the toxigenic fungi and the production of the mycotoxins, could be promising for the bioconservation of food. These strains could be used in combination with starters in fermented foods, and the fermented freeze-dried solution could be used in both formulation and coating of foods. Therefore, these results provide new knowledge for the biotechnological use of BCAs, since they could increase the postharvest shelf-life of food, contributing to meet the demand of consumers, reducing the agricultural use of chemicals and increasing natural alternatives.

Further investigations are needed to clear up whether the efficacy of BCAs might be enhanced by adding more ingredients and other bio-products that can have synergistic effects.

Finally, the application of BCAs for the biocontrol of mycotoxins should be implemented combined with suitable farming practices and appropriate postharvest management.

\section{Materials and Methods}

\subsection{Chemicals and Reagents}

$\mathrm{AFB}_{1}$, OTA, p-coumaric, hydroxycinnamic acid, benzoic acid, DL-3-phenyllactic acid, 1,2-dihydroxybenzene, and 3,4-dihydroxyhydrocinnamic acid were obtained from SigmaAldrich (St. Louis, MO, USA). Phenyllactic acid (PLA) was provided from BaChem (Weil am Rhein, Germany). Protocatechuic acid was acquired from HWI Pharma Services (Ruelzheim, Germany). $\mathrm{AFB}_{1}$ and OTA had a purity above 99\%, while the rest of the analytes had a purity of $95 \%$. Culture media potato dextrose broth (PDB), potato dextrose agar (PDA), plate count agar (PCA), nutrient broth (NB), and triptone soy broth (TSB) were achieved from Liofilchem Bacteriology Products (Teramo, Italy).

Ethyl acetate, methanol, acetonitrile (ACN), and formic acid (analytical grade, purity $>$ 98\%) were obtained from Fisher Scientific (Hudson, NH, USA). C18, ammonium formate, magnesium sulfate $(\mathrm{MgSO} 4)$, and sodium chloride $(\mathrm{NaCl})$ were obtained from Sigma-Aldrich (St. Louis, MO, USA). Deionized water used ( $<18 \mathrm{M} \Omega / \mathrm{cm}$ resistivity) was produced with a Milli-Q purification system (Millipore Corp., Bedford, MA, USA).

\subsection{Microbiological Culture}

The strains of Penicillium verrucosum CECT 2913 and Botytis cinerea CECT 20973 were obtained from the Spanish Type Culture Collection (Science Park of the University of Valencia, Paterna, València, Spain), which is the public reference center for microbial resources in Spain. The strains of Aspergillus flavus ITEM 8111, Alternaria alternata ITEM 8121, and six Fusarium strains (Fusarium graminearum ITEM 126, Fusarium poae ITEM 9151, Fusarium langsethiae ITEM 11031, Fusarium verticillioides ITEM 12043, Fusarium proliferatum ITEM 12072, and Fusarium sporotrichioides ITEM 12168) were obtained from the Agro-Food Microbial Culture Collection of the Institute of Sciences and Food Production (ISPA, Bari, Italy). These fungi were cryopreserved in sterile liquid medium PDB with $30 \%$ glycerol at $-80^{\circ} \mathrm{C}$. Prior to antifungal studies on solid and liquid medium, the strains were defrosted and grown in solid medium PDA at $25^{\circ} \mathrm{C}$, with periodic transfers to new PDA plates. These pathogens were selected to cover a representative sample of fungi of the genera Aspergillus, Penicillium, Fusarium, and Botrytis.

A total of twenty biocontrol strains: Paenibacillus polymyxa CECT 153, Paenibacillus polymyxa CECT 155, Bacillus thuringiensis CECT 197, Paenibacillus chibensis CECT 375, Paenibacillus alvei CECT 2, Bacillus licheniformis CECT 20, Bacillus megaterium CECT 44, Bacillus subtilis CECT 499, Bacillus amyloliquefaciens CECT 493, Pantoea agglomerans CECT 850, Streptomyces griseus CECT 3276, Streptomyces calvus CECT 3271, Pseudomonas syringae CECT 312, Pseudomonas syringae CECT 4390, Pseudomonas syringae CECT 4393, Candida 
sake CECT 1044, Candida sake CECT 10034, Candida oleophila CECT 11891, Metschnikowia pulcherrima CECT 1691, and Metschnikowia pulcherrima CECT 10408 were also obtained from the Spanish Type Culture Collection (Table 7) and kept in frozen glycerol (30\%) stocks at $-80{ }^{\circ} \mathrm{C}$ until analysis. The antifungal activity of these 20 biocontrol strains was studied against the 10 toxigenic fungi belonging to the genera Aspergillus, Penicillium, Fusarium, and Alternaria described above. These biocontrol strains were selected mainly because of the scarce data in the literature, which has focused almost exclusively on the use of LABs.

Table 7. Information on the origin of strains used as biocontrol agents (available at the website of the Spanish Type Culture Collection).

\begin{tabular}{|c|c|c|c|c|c|}
\hline Biocontrol Agent & CECT ID & Source of Isolation & Year & Country & First Description \\
\hline P. polymixa & 153 & Water & 1981 & Unknown & Prazmowski, 1880 \\
\hline P. polymixa & 155 & Decomposing plants and soil & 1974 & Unknown & Prazmowski, 1880 \\
\hline B. thuringiensis & 197 & $\begin{array}{c}\text { Ephestia kuhniella } \\
\text { (Mediterranean flour moth) }\end{array}$ & 1980 & Unknown & Berliner, 1915 \\
\hline P. chibensis & 375 & Unknown & 1979 & Unknown & Shida et al. 1997 \\
\hline P. alvei & 2 & Foulbrood in bees & 1974 & Unknown & Cheshire and Cheyne 1885 \\
\hline B. licheniformis & 20 & Unknown & 1984 & Unknown & Weigmann, 1898 \\
\hline B. megaterium & 44 & Unknown & 1980 & Unknown & Bary, 1884 \\
\hline B. subtilis & 499 & Unknown & 1982 & Unknown & Ehrenberg, 1835 \\
\hline B. amyloliquefaciens & 493 & $\begin{array}{l}\text { Bacterial amylase HT } \\
\text { concentrate }\end{array}$ & 1981 & United States & Priest et al. 1987 \\
\hline P. agglomerans & 850 & Knee laceration & 1987 & Unknown & Ewing and Fife, 1972 \\
\hline S. griseus & 3276 & Soil & 1987 & United States & Krainsky, 1914 \\
\hline S. calvus & 3271 & Soil & 1986 & India & Backus et al. 1957 \\
\hline P. syringae & 312 & Nicotania tabacum & 1978 & Hungary & van Hall 1902 \\
\hline P. syringae & 4390 & Phaseolus vulgaris & 1992 & Hungary & van Hall 1902 \\
\hline P. syringae & 4393 & Lycopersicon esculentum & 1992 & United Kingdom & van Hall 1902 \\
\hline C. sake & 1044 & Lambic beer & 1985 & Belgium & $\begin{array}{l}\text { van Uden \& H.R. } \\
\text { Buckley } 1983\end{array}$ \\
\hline C. sake & 10034 & Feces of sheep & 1991 & Spain & $\begin{array}{l}\text { van Uden \& H.R. } \\
\text { Buckley } 1983\end{array}$ \\
\hline C. oleophila & 11891 & Fruit of Olea europea (olive) & 2001 & Unknown & Montrocher, 1967 \\
\hline M. pulcherrima & 1691 & Fruit of Phoenix dactylifera (date) & 1989 & Egypt & Pitt \& M.W. Miller 1968 \\
\hline M. pulcherrima & 10408 & Orange & 1991 & Spain & Pitt \& M.W. Miller 1968 \\
\hline
\end{tabular}

Prior to the fermentation process, the strains were cultivated in different mediums at different temperatures according to the best conditions for their growth. P. polymyxa (CECT 153 and CECT 155), B. thuringiensi, P. chibensis, P. alvei, B. megaterium, B. subtilis, and P. agglomerans were inoculated with NB (13 g in $1000 \mathrm{~mL}$ of distilled water) at $30^{\circ} \mathrm{C}$, while B. licheniformis and B. amyloliquefaciens were inoculated in the same medium at $37^{\circ} \mathrm{C}$. S. griseus and $S$. calvus were inoculated with yeast extract-malt extract ( $4 \mathrm{~g}$, malt extract $10 \mathrm{~g}$, glucose $4 \mathrm{~g}$ ) at $30{ }^{\circ}$ C. P. syringae (CECT 312, CECT 4390, and CECT 4393) were inoculated with TSB (15 g of triptone soy broth in $1000 \mathrm{~mL}$ of distilled water) at $26{ }^{\circ} \mathrm{C}$ and C. sake (CECT 1044 and CECT 10034), C. oleophila and M. pulcherrima (CECT 1691 and CECT 10408) were inoculated with glucose peptone-yeast extract ( $40 \mathrm{~g}$ of glucose, $5 \mathrm{~g}$ of Triptone, $5 \mathrm{~g}$ of yeast extract in $1000 \mathrm{~mL}$ of distilled water) at $24{ }^{\circ} \mathrm{C}$.

\subsection{Process of Obtaining Cell-Free Supernatant (CFS)}

After their defrost and recovery, the biocontrol strains were cultured for $12 \mathrm{~h}$ in the media described in 4.2 until exponential phase growth. Then, the strains were placed in $50 \mathrm{~mL}$ of NB liquid medium (final concentration $10^{7} \mathrm{CFU} / \mathrm{mL}$ ) and maintained at $30{ }^{\circ} \mathrm{C}$ for $72 \mathrm{~h}$. After this time, the liquid medium was centrifuged for $10 \mathrm{~min}$ at $7000 \mathrm{rpm}$ to obtain CFS. These CFS were frozen for $24 \mathrm{~h}$ at $-80{ }^{\circ} \mathrm{C}$ prior to lyophilization (FreeZone 2.5 L Benchtop Freeze Dry System, Labconco, Kansas City, MO, USA) and then stored at $-19{ }^{\circ} \mathrm{C}[16,19]$. 


\subsection{Qualitative Antifungal Activity of Biocontrol Strains}

The effect of the BCAs on the growth inhibition of different fungi (listed in Table 2) was studied by the agar diffusion method and overlay assay. In the agar diffusion assay, PDA medium plates were inoculated with the 10 fungi described in Section 4.2 and after making $1 \mathrm{~cm}$ wells, these were loaded with $50 \mu \mathrm{L}$ of lyophilized and resuspended CFS at a concentration of $100 \mathrm{~g} / \mathrm{L}$. After incubating the plates, the appearance of inhibition halos was observed $[14,16]$.

In the overlay assay, the center of the PCA plates was contaminated with a suspension of the different $\mathrm{BCA}$, and after solidification, they were covered with PDA medium previously inoculated with spores of the different toxigenic fungi. After incubating the plates, the appearance of inhibition halos was observed and measured $[17,20]$.

\subsection{Quantitative Antifungal Activity of Biocontrol Strains}

Sterile 96-well microplates were used for this assay as described by Luz et al. (2020) [16]. The objective was to determine the MIC and minimum fungicide concentration (MFC). In the wells, $100 \mu \mathrm{L}$ of CFS suspended at doses between 0.1 and $100 \mathrm{~g} / \mathrm{L}$ were deposited together with $100 \mu \mathrm{L}$ of PDB liquid medium contaminated with $5 \times 10^{4}$ spores $/ \mathrm{mL}$ of the fungi described in Section 4.2. Microplates were incubated in the dark at $25^{\circ} \mathrm{C}$ for $72 \mathrm{~h}$, and MIC was considered as the lowest concentration of CFS at which no fungal growth was visually detected. To determine the MFC, $10 \mu \mathrm{L}$ from each well with concentrations above the MIC were seeded onto PDA medium plates and incubated $\left(25^{\circ} \mathrm{C}, 72 \mathrm{~h}\right.$.), and the presence or absence of fungal growth was observed.

\subsection{Determination of Organic and Phenolic Acids in CFS}

A high-performance liquid chromatography (HPLC) system (Agilent 1100 Series HPLC System, Agilent Technologies, Palo Alto, CA, USA) was used to analyze the organic acids. The samples were diluted in distilled water and injected using a Spherisorb S5 ODS2 reversed-phase column $(4.6 \mathrm{~mm} \times 250 \mathrm{~mm}, 5 \mu \mathrm{m})$ (Waters Corp., Milford, MA, USA). The mobile phase was acidified water at $\mathrm{pH} 2.1(0.6 \mathrm{~mL} / \mathrm{min})$. The diode array detector (DAD) was set to a wavelength of $210 \mathrm{~nm}$.

Prior to phenolic acid analysis, interferences in CFS were removed by the QuEChERS method [15], and the resulting extracts were resuspended with $1 \mathrm{~mL} \mathrm{H}_{2} \mathrm{O}: \mathrm{ACN}(90: 10 \mathrm{v} / \mathrm{v})$. For the determination, samples were injected into an Agilent 1200 HPLC system (Agilent Technologies, Santa Clara, CA, USA) with a Gemini C18 column (50 mm $\times 2 \mathrm{~mm}, 100 \AA$, particle size of $3 \mu \mathrm{m}$; Phenomenex). The mobile phases consisted of water (A) and ACN (B), both with $0.1 \%$ formic acid at $0.3 \mathrm{~mL} / \mathrm{min}$ with gradient $(0 \mathrm{~min}, 5 \% \mathrm{~B} ; 30 \mathrm{~min}, 95 \% \mathrm{~B}$; $35 \mathrm{~min}, 5 \% \mathrm{~B})$. A Q-TOF-MS (6540 Agilent Ultra High-Definition Accurate Mass), with an Agilent Dual Jet Stream electrospray ionization interface (Dual AJS ESI) in negative mode, was used for mass spectrometry (MS) analysis [19,31,32].

\subsection{Antimycotoxigenic Activity of CFS}

The antimycotoxigenic activity of the CFS by biocontrol microorganisms was evaluated. This assay was carried out by using 20 biocontrol strains (previously listed). For each BCAs, sterile $15 \mathrm{~mL}$ Falcon tubes were provided with $5 \mathrm{~mL}$ of NB contaminated with $1 \mathrm{mg} / \mathrm{L}$ of $\mathrm{AFB}_{1}$ and $1 \mathrm{mg} / \mathrm{L}$ OTA. Then, $50 \mu \mathrm{L}$ of a NB suspension with recently grown bacteria ( $48 \mathrm{~h}$ ago) were added. To make this NB with the mycotoxins, $1 \mathrm{~L}$ of sterile NB was prepared to which the appropriate amounts of mycotoxin standard (Sigma-Aldrich (St. Louis, MO, USA) were added. Tubes were kept in an oven at $30^{\circ} \mathrm{C}$ for $48 \mathrm{~h}$ while control tubes $(0 \mathrm{~h})$ were analyzed immediately after preparation. Finally, tubes were centrifuged at $4000 \mathrm{rpm}$ for $15 \mathrm{~min}$ at $4{ }^{\circ} \mathrm{C}$, and supernatants were filtered $(0.22 \mu \mathrm{m})$, and vialized for mycotoxin determination by LC-MS/MS-QTRAP, as explained below. 


\subsection{Determination of $A F B_{1}$ and OTA by LC-MS/MS Spectrometry}

For mycotoxin analysis, the samples were injected into an HPLC coupled to a 3200QTRAP mass spectrometer (Applied Biosystems, Foster City, CA, USA). The column used to separate mycotoxins was a Gemini NX C18 column $(150 \times 2.0 \mathrm{~mm}$ I.D, $3.0 \mathrm{~mm}$, Phenomenex, Palo Alto, CA, USA). The mobile phases consisted of water (A) and ACN (B), both with $0.1 \%$ formic acid and $5 \mathrm{mM}$ ammonium formate at $0.25 \mathrm{~mL} / \mathrm{min}$ with a linear gradient. The ions transitions used for the $\mathrm{AFB}_{1}$ and OTA identification and quantification were $m / z 313.1 / 241.3$ and $284.9\left(\mathrm{AFB}_{1}\right)$ and $m / z$ 404.3/102.1 and 358.1 (OTA) [33].

\subsection{Statistical Analysis}

Statistical analysis was performed using the InfoStat software version 2008. The assays were realized in triplicates, and the differences between control and treated groups were analyzed by Student's t-test, while the differences between the groups were analyzed by one-way ANOVA test. The significance levels were set at $p \leq 0.05$.

Author Contributions: J.M.Q. conceived and proposed the idea. J.M.Q. and G.M. designed the study. G.M. acquired funds. F.I. performed the experiments and analysed the data. P.V.-D. wrote, and revised the paper. F.I., J.C. and C.L. contributed to the writing of the manuscript. All authors have read and agreed to the published version of the manuscript.

Funding: This research study was supported by the Ministry of Science and Innovation (PID2019108070RB-100) and by the project Prometeo/2018/126 supported by Generalitat Valenciana.

Acknowledgments: The research was supported by the European Project (H2020-Research and Innovation Action) MycoKey "Integrative and innovative actions for mycotoxin management in the food and feed chain" GA 678781.

Conflicts of Interest: The authors declare no conflict of interest.

\section{References}

1. Saladino, F.; Luz, C.; Manyes, L.; Franzón, M.F.; Meca, G. In Vitro antifungal activity of lactic acid bacteria against mycotoxigenic fungi and their application in loaf bread shelf life improvement. Food Control. 2016, 67, 273-277. [CrossRef]

2. Yang, J.; Li, J.; Jiang, Y.; Duan, X.; Qu, H.; Yang, B.; Chen, F.; Sivakumar, D. Natural Occurrence, Analysis, and Prevention of Mycotoxins in Fruits and their Processed Products. Crit. Rev. Food Sci. Nutr. 2013, 54, 64-83. [CrossRef] [PubMed]

3. Rodríguez-Carrasco, Y.; Moltó, J.C.; Mañes, J.; Berrada, H. Exposure assessment approach through mycotox-in/creatinine ratio evaluation in urine by GC-MS/MS. Food Chem. Toxicol. 2014, 72, 69-75. [CrossRef] [PubMed]

4. Zain, M.E. Impact of mycotoxins on humans and animals. J. Saudi Chem. Soc. 2011, 15, 129-144. [CrossRef]

5. Varsha, K.K.; Nampoothiri, K.M. Appraisal of lactic acid bacteria as protective cultures. Food Control. 2016, 69, 61-64. [CrossRef]

6. IARC-International Agency for Research on Cancer. Monographs on the evaluation of carcinogenic risks to humans. In A Review of Biological Agents for Human Carcinogens; IARC-International Agency for Research on Cancer: Lyon, France, 2012.

7. Quiles, J.M.; Nazareth, T.D.M.; Luz, C.; Luciano, F.B.; Mañes, J.; Meca, G. Development of an antifungal and antimycotox-igenic device containing allyl isothiocyanate for silo fumigation. Toxins 2019, 11, 137. [CrossRef]

8. Marin, S.; Ramos, A.J.; Cano-Sancho, G.; Sanchis, V. Mycotoxins: Occurrence, toxicology and exposure assessment. Food Chem. Toxicol. 2013, 60, 218-237. [CrossRef]

9. IARC (International Agency for Research on Cancer). Some traditional herbal medicines, some mycotoxins, naph-thalene and styrene. In Monograph on the Evaluation of Carcinogenic Risk to Humans; IARC: Lyon, France, 2002.

10. Vila-Donat, P.; Marín, S.; Sanchis, V.; Ramos, A. A review of the mycotoxin adsorbing agents, with an emphasis on their multi-binding capacity, for animal feed decontamination. Food Chem. Toxicol. 2018, 114, 246-259. [CrossRef]

11. Vandghanooni, S.; Forouharmehr, A.; Eskandani, M.; Barzegari, A.; Kafil, V.; Kashanian, S.; Dolatabadi, J.E.N. Cytotoxicity and DNA Fragmentation Properties of Butylated Hydroxyanisole. DNA Cell Biol. 2013, 32, 98-103. [CrossRef]

12. Izzo, L.; Luz, C.; Ritieni, A.; Mañes, J.; Meca, G. Whey fermented by using Lactobacillus plantarum strains: A promising approach to increase the shelf life of pita bread. J. Dairy Sci. 2020, 103, 5906-5915. [CrossRef]

13. Nešić, K.; Habschied, K.; Mastanjević, K. Possibilities for the Biological Control of Mycotoxins in Food and Feed. Toxins 2021, 13, 198. [CrossRef]

14. Varsha, K.K.; Priya, S.; Devendra, L.; Nampoothiri, K.M. Control of Spoilage Fungi by Protective Lactic Acid Bacteria Displaying Probiotic Properties. Appl. Biochem. Biotechnol. 2014, 172, 3402-3413. [CrossRef]

15. Brosnan, B.; Coffey, A.; Arendt, E.K.; Furey, A. The QuEChERS approach in a novel application for the identification of antifungal compounds produced by lactic acid bacteria cultures. Talanta 2014, 129, 364-373. [CrossRef] 
16. Luz, C.; D’Opazo, V.; Quiles, J.; Romano, R.; Mañes, J.; Meca, G. Biopreservation of tomatoes using fermented media by lactic acid bacteria. LWT 2020, 130, 109618. [CrossRef]

17. Guimarães, A.; Santiago, A.; Teixeira, J.A.; Venâncio, A.; Abrunhosa, L. Antiaflatoxigenic effect of organic acids produced by Lactobacillus plantarum. Int. J. Food Microbiol. 2018, 264, 31-38. [CrossRef]

18. Omedi, J.O.; Huang, W.; Zheng, J. Effect of sourdough lactic acid bacteria fermentation on phenolic acid release and anti-fungal activity in pitaya fruit substrate. LWT Food Sci. Technol. 2019, 111, 309-317. [CrossRef]

19. Nazareth, T.D.M.; Luz, C.; Torrijos, R.; Quiles, J.M.; Luciano, F.B.; Mañes, J.; Meca, G. Potential Application of Lactic Acid Bacteria to Reduce Aflatoxin B1 and Fumonisin B1 Occurrence on Corn Kernels and Corn Ears. Toxins 2019, 12, 21. [CrossRef]

20. Calvo, H.; Marco, P.; Blanco, D.; Oria, R.; Venturini, M. Potential of a new strain of Bacillus amyloliquefaciens BUZ-14 as a biocontrol agent of postharvest fruit diseases. Food Microbiol. 2017, 63, 101-110. [CrossRef] [PubMed]

21. Rizzello, C.G.; Cassone, A.; Coda, R.; Gobbetti, M. Antifungal activity of sourdough fermented wheat germ used as an in-gredient for bread making. Food Chem. 2011, 127, 952-959. [CrossRef] [PubMed]

22. Rodríguez, H.; Landete, J.M.; Rivas, B.D.L.; Muñoz, R. Metabolism of food phenolic acids by Lactobacillus plantarum CECT 748T. Food Chem. 2008, 107, 1393-1398. [CrossRef]

23. Dagnas, S.; Gauvry, E.; Onno, B.; Membré, J.-M.; Stéphane, G. Quantifying Effect of Lactic, Acetic, and Propionic Acids on Growth of Molds Isolated from Spoiled Bakery Products. J. Food Prot. 2015, 78, 1689-1698. [CrossRef] [PubMed]

24. Lavermicocca, P.; Valerio, F.; Visconti, A. Antifungal Activity of Phenyllactic Acid against Molds Isolated from Bakery Products. Appl. Environ. Microbiol. 2003, 69, 634-640. [CrossRef] [PubMed]

25. Silva, B.; de Souza, M.; Badiale-Furlong, E. Antioxidant and antifungal activity of phenolic compounds and their relation to aflatoxin B1 occurrence in soybeans (Glycine max L.). J. Sci. Food Agric. 2019, 100, 1256-1264. [CrossRef] [PubMed]

26. Romero-Cortes, T.; Pérez España, V.H.; López Pérez, P.A.; Rodríguez-Jimenes, G.D.C.; Robles-Olvera, V.J.; Aparicio Burgos, J.E.; Cuervo-Parra, J.A. Antifungal activity of vanilla juice and vanillin against Alternaria alternate. CyTA J. Food 2019, 17, 375-383. [CrossRef]

27. Topcu, A.; Bulat, T.; Wishah, R.; Boyaci, I. Detoxification of aflatoxin B1 and patulin by Enterococcus faecium strains. Int. J. Food Microbiol. 2010, 139, 202-205. [CrossRef]

28. Farzaneh, M.; Shi, Z.Q.; Ghassempour, A.; Sedaghat, N.; Ahmadzadeh, M.; Mirabolfathy, M.; Javan-Nikkhah, M. Aflatox-in B1 degradation by Bacillus subtilis UTBSP1 isolated from pistachio nuts of Iran. Food Control. 2012, 23, 100-106. [CrossRef]

29. Fan, Y.; Zhao, L.; Ma, Q.; Li, X.; Shi, H.; Zhou, T.; Zhang, J.; Ji, C. Effects of Bacillus subtilis ANSB060 on growth performance, meat quality and aflatoxin residues in broilers fed moldy peanut meal naturally contaminated with aflatoxins. Food Chem. Toxicol. 2013, 59, 748-753. [CrossRef]

30. Shukla, S.; Park, J.H.; Chung, S.H.; Kim, M. Ochratoxin A reduction ability of biocontrol agent Bacillus subtilis isolated from Korean traditional fermented food Kimchi. Sci. Rep. 2018, 8, 1-10. [CrossRef]

31. Khosravi, F.; Rastakhiz, N.; Iranmanesh, B.; Olia, S.S.S.J. Determination of Organic Acids in Fruit juices by UPLC. Int. J. Life Sci. 2015, 9, 41-44. [CrossRef]

32. Denardi-Souza, T.; Luz, C.; Mañes, J.; Badiale-Furlong, E.; Meca, G. Antifungal effect of phenolic extract of fermented rice bran with Rhizopus oryzae and its potential use in loaf bread shelf life extension. J. Sci. Food Agric. 2018, 98, 5011-5018. [CrossRef]

33. Luz, C.; Carbonell, R.; Quiles, J.M.; Torrijos, R.; de Melo Nazareth, T.; Mañes, J.; Meca, G. Antifungal activity of peracetic ac-id against toxigenic fungal contaminants of maize and barley at the postharvest stage. LWT. Food Sci. Tech. 2021, 148, 111754. [CrossRef] 